\title{
Influence of Strain and Stress Triaxiality on the Fracture Behavior of GB 35CrMo Steel during Hot Tensile Testing
}

\author{
Zheng Li, Yajun Zhou $(\mathbb{D}$, and Sanxing Wang \\ College of Mechanical and Electrical Engineering, Central South University, Changsha 410083, China \\ Correspondence should be addressed to Yajun Zhou; zhouyjun@csu.edu.cn
}

Received 4 June 2018; Revised 27 August 2018; Accepted 4 September 2018; Published 1 November 2018

Academic Editor: Davide Palumbo

Copyright (c) 2018 Zheng Li et al. This is an open access article distributed under the Creative Commons Attribution License, which permits unrestricted use, distribution, and reproduction in any medium, provided the original work is properly cited.

\begin{abstract}
To better understand cavitation nucleation and crack initiation in 35CrMo steel during high-temperature tensile processing and the effect of stress triaxiality on its fracture behaviors, uniaxial and notch high-temperature tensile tests were performed. The microstructure, fracture morphology, fracture strain, and stress triaxiality of the tested 35CrMo steel were then characterized and discussed. The results showed that crack formation in 35CrMo steel included stages of nucleation, growth, and microcavity aggregation. Scanning electron microscopy and energy-dispersive X-ray spectroscopy demonstrated that crack formation was closely related to the presence of steel inclusions. High-temperature tensile testing of samples with different notch radii showed that the fracture strain of 35CrMo steel was decreased with increasing stress triaxiality, that is, increased stress levels corresponded to decreased material plasticity. In addition, the recrystallization degree was decreased with increased stress triaxiality, and the grain size growth was slowed. The failure of 35CrMo steel occurred via ductile fracture, and low stress triaxiality, and high temperature conditions induced large and deep dimples on the fracture surface.
\end{abstract}

\section{Introduction}

Because it offers excellent comprehensive mechanical properties, 35CrMo steel is often used to manufacture important structural parts, such as the rotors of turbo generators, spindles, transmission shafts with heavy loads, and largesection parts [1-4]. To manufacture these key components, it is necessary to consider the complexity of the forging process. Crack initiation can occur in materials when the forging deformation process parameters are incompatible with the material properties. To avoid cracks and holes, it is important to study the factors affecting the properties and fracture mechanism of $35 \mathrm{CrMo}$ steel during hot working $[5,6]$.

The study of the effects of crack initiation and stress state on ductile fractures began with Ludwik and Scheu [7], who assumed that ductile metal fracture was controlled by the stress-strain curve. Correlative studies have shown that crack formation during thermoforming always occurred by the nucleation, growth, and coalescence of microcavities, as shown in Figure $1[8,9]$. From the perspective of mesoscopic damage mechanics, studies have confirmed a correlation between the presence of cracks and second-phase particle inclusions [10]. Recently, Pardoen and Hutchinson [9], Benzerga [11], and Gao and Kim [12] demonstrated that the Gologanu-Leblond-Devaux model showed significantly improved accuracy in its description of void growth and the corresponding material behavior during ductile fracture. In addition, similar relationships between material fracture and thermal processing parameters have been reported for EH36 alloys [13], Ni-based superalloys [14], Al-7.0\%Si-0.3\%Mg foundry $\mathrm{Al}$ alloys [15], and other alloys [16, 17]. These successful studies have demonstrated that thermotensile tests are important in understanding metal thermoforming and are powerful tools that can guide thermal processing. Zhang et al. [18] and Duan and Liu [19] also used the theory of mesoscopic damage mechanics to study the ductile fracture behavior of 316LN stainless steel.

Stress triaxiality is the most commonly used stress-state parameter for ductile metals. Several scholars have confirmed that it can reflect complex material stress states. McClintock [20] and Rice and Tracey [21] studied the microstructural growth and identified strong relationships between stress triaxiality and ductile metal fracture strain and behavior. Hancock and Mackenzie [22] also found via 


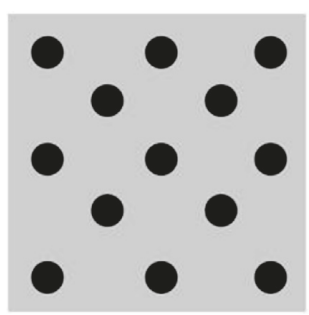

(a)

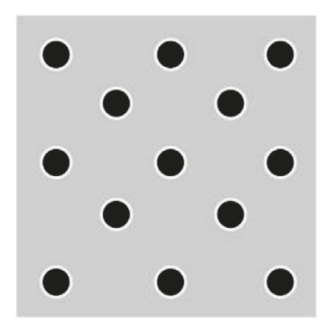

(b)

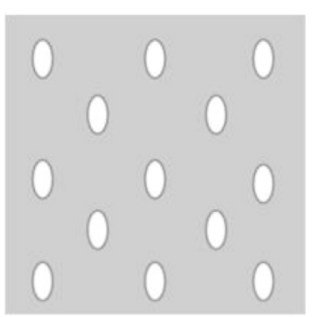

(c)

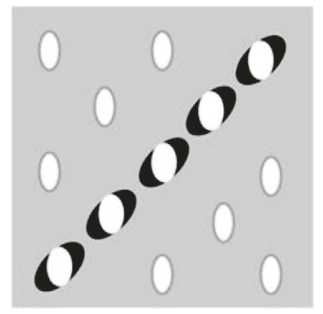

(d)

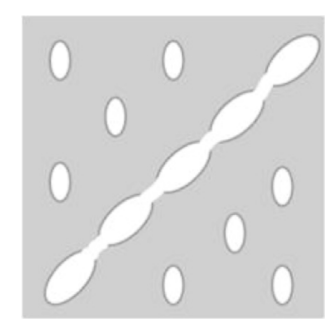

(e)

FIgURe 1: Process of crack formation: (a) inclusions, (b) cavity nucleation, (c) cavity growth, (d) cavity necking, and (e) cavity coalescence.

a series of notched-sample tensile tests that metal ductility was affected by the triaxiality state of the sample. Recent experimental and numerical studies by Mirza et al. [23] on pure Fe, mild steel, and the BS1474 Al alloy in a wide range of strain rates, and by Bao and Wierzbicki $[24,25]$ and Bao $[26,27]$ on $2024 \mathrm{Al}$ alloy during quasistatic loading reaffirmed the strong relationship among equivalent strain, stress triaxiality, and crack formation. In these studies, stress triaxiality was used to define the failure function of the material. The hot tensile tests of $35 \mathrm{CrMo}$ steel are only found in Xiao's study. Xiao et al. [28] studied the hot tensile and fracture behaviors of $35 \mathrm{CrMo}$ steel at high temperatures and strain rates. However, the initiation and propagation of cracks under different strain and stress states have not been reported. Therefore, the effect of strain and stress triaxiality on the fracture behavior of $35 \mathrm{CrMo}$ steel under hot tensile deformation requires further study.

Hence, in this paper, the effects of strain, temperature, and stress triaxiality on the fracture behavior of $35 \mathrm{CrMo}$ steel were investigated by uniaxial and notched hightemperature tensile testing. The microstructure evolution and fracture behavior of 35CrMo steel under different tensile conditions were studied after stretching by means of metallographic structure and fracture scanning analysis.

\section{Experimental Materials and Procedures}

2.1. High-Temperature Tensile Test. A commercial 35CrMo alloy with the composition $0.34 \mathrm{C}-0.21 \mathrm{Si}-0.56 \mathrm{Mn}-0.95 \mathrm{Cr}-$ 0.19Mo-0.0051S-0.019Si-(bal.) Fe (wt.\%) was used in this investigation. The shape and size of the high-temperature tensile samples are shown in Figure 2.

Tensile tests were performed using a Gleeble 3500 testing machine (Huazhong University of Science and Technology, Wuhan, China). Hot tensile tests of the samples shown in Figure 2 (a) were performed at $1000^{\circ} \mathrm{C}$ and the strain rate of $0.5 \mathrm{~s}^{-1}$ to the tensile strain values of $0.2,0.4,0.54,0.6,0.8$, and 0.97. Hot tensile tests of the samples shown in Figure 2(b) were performed at temperatures of $850^{\circ} \mathrm{C}, 950^{\circ} \mathrm{C}, 1050^{\circ} \mathrm{C}$, and $1150^{\circ} \mathrm{C}$ with the strain rate of $0.5 \mathrm{~s}^{-1}$ and notch radii of $1 \mathrm{~mm}$, $2 \mathrm{~mm}, 4 \mathrm{~mm}$, and $6 \mathrm{~mm}$. All samples were heated to $1150^{\circ} \mathrm{C}$ at $10^{\circ} \mathrm{C} / \mathrm{s}$, soaked for $120 \mathrm{~s}$ to eliminate thermal gradients, and then cooled to the set deformation temperature at $10^{\circ} \mathrm{C} / \mathrm{s}$. Before tensile testing, samples were maintained at the deformation temperature for $120 \mathrm{~s}$. Then, the tensile tests were performed as shown in Figure 3. Immediately after the tensile tests, each sample was quenched in Ar to retain the deformed microstructure. The deformed samples were cut in the axial direction, polished, and etched in a solution consisting of picric acid $(5 \mathrm{~g}), \mathrm{H}_{2} \mathrm{O}(100 \mathrm{~mL})$, and $\mathrm{HCl}(1 \mathrm{~mL})$ at $60-80^{\circ} \mathrm{C}$ for $3-8 \mathrm{~min}$ to perform both optical microscopy (OM, Olympus, Tokyo, Japan) and SEM (EVO MA10, EISS, Jena, Germany) observations.

2.2. Initial Stress Triaxiality. The necking phenomenon of stretched materials is complicated. In this case, the complex stress can be simplified to the three-dimensional stress state shown in Figure 4. When the stress states of the material changes, the plastic deformation and fracture strain of the materials will also change. To further understand the three-dimensional stress and its relationship to void initiation, the parameter $R_{\sigma}$, known as the stress triaxiality, is introduced, and the following expression is given [29]:

$$
R \sigma=\frac{1}{3}+\ln \left(\frac{a^{2}+2 a R-r^{2}}{2 a R}\right),
$$

where $a$ is the radius of the minimum cross section of the part undergoing necking, $r$ is the radial value from the axis of the smallest cross section of the neck to the edge, and $R$ is the curvature radius of the minimum cross section of the necking zone. When $r=0$, the maximum $R_{\sigma}$ value is obtained:

$$
R \sigma=\frac{1}{3}+\ln \left(1+\frac{a}{2 R}\right) .
$$

During high-temperature tensile testing, the stress triaxiality $R_{\sigma}$ is the highest in the center part $(r=0)$ of the necking region, and the holes form in the center for the maximum stress triaxiality, and then connection grows and then diffuse to the surface of the sample, eventually leading to fracture of the sample. There is a strong correlation between stress triaxiality and crack initiation in sample fracture. As shown in Figure 5(e), large and deep interconnected cracks appear in the center of the necking region. When the crack occurs, the axial tensile stress plays a leading role in the crack propagation, and the crack propagates along the direction of the maximum tensile stress.

The initial central stress triaxiality $R_{\sigma}$ can be calculated by inserting the initial radius $r$ and the initial notch radius $R$ of the minimum section into formula (1). The initial minimum radius $r$ of all notched samples is equal to $3 \mathrm{~mm}$, 


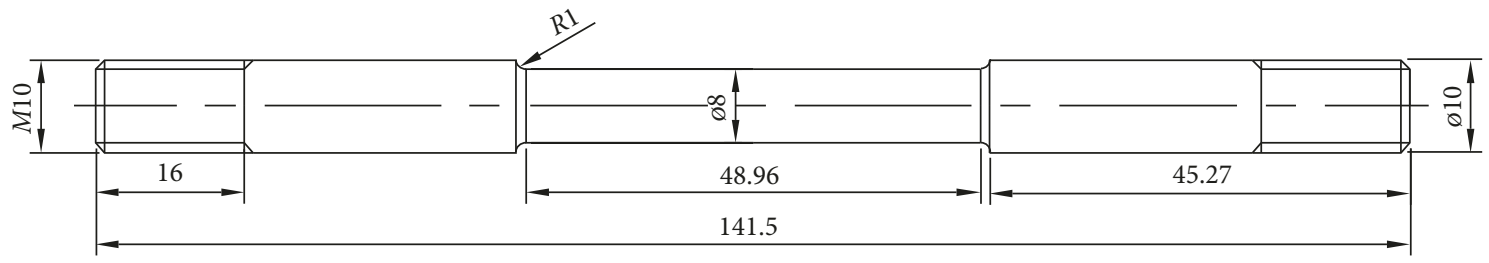

(a)

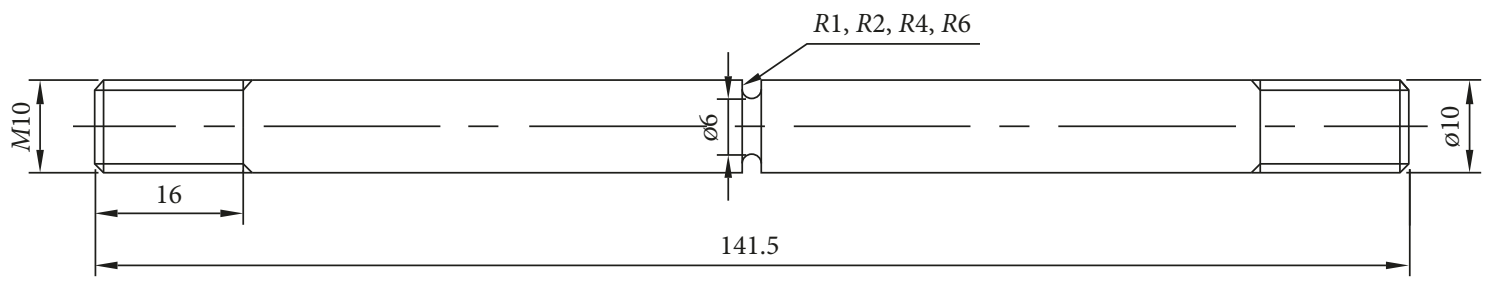

(b)

FIGURE 2: Scheme of the tensile sample (all dimensions are in $\mathrm{mm}$ ): (a) uniaxial high-temperature tensile; (b) notch high-temperature tensile.

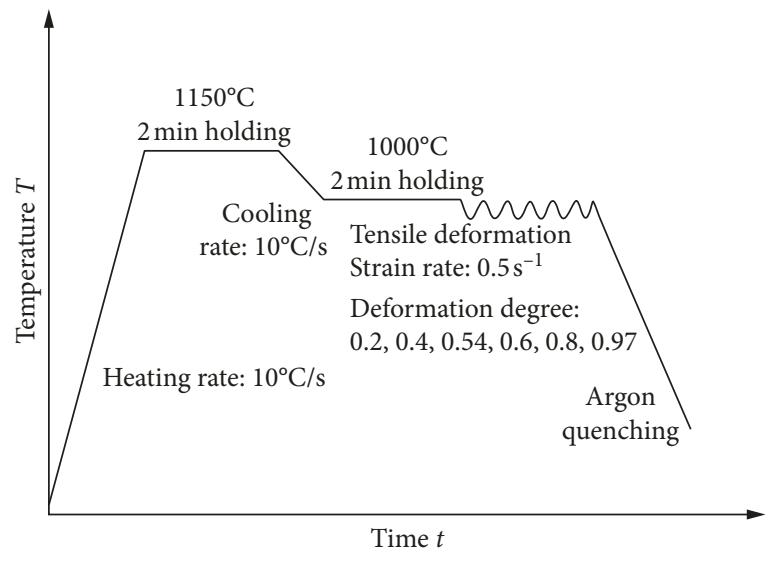

(a)

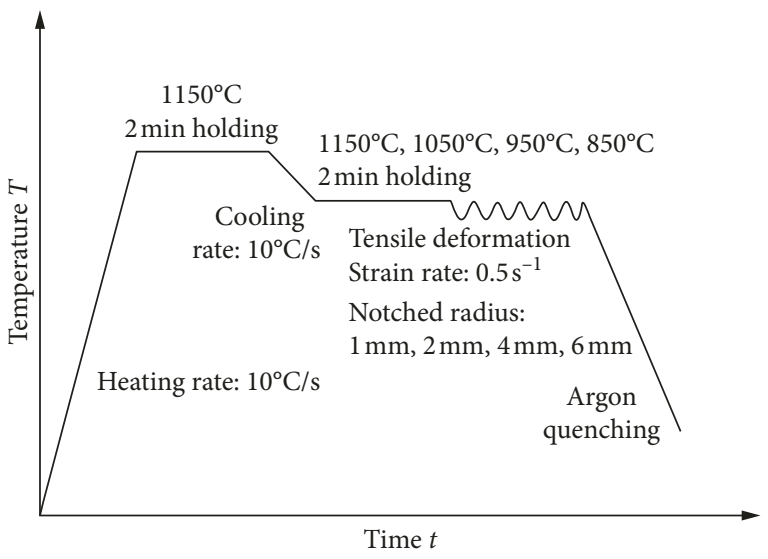

(b)

FIGURE 3: Experimental procedure used for hot tensile tests: (a) uniaxial high-temperature tensile; (b) notch high-temperature tensile.

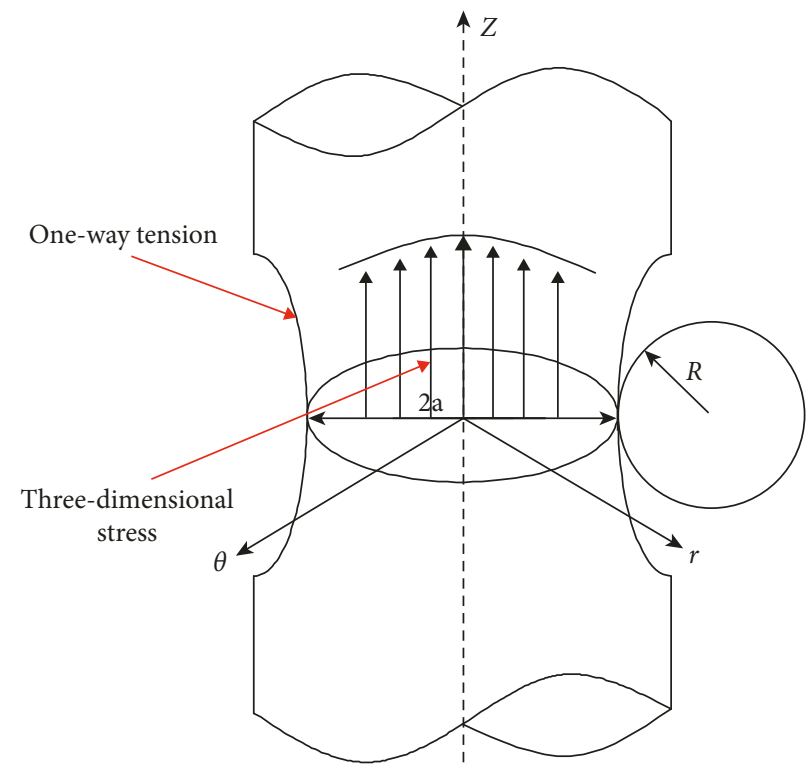

Figure 4: Three-dimensional stress of a part that undergoes necking during tensile testing. 


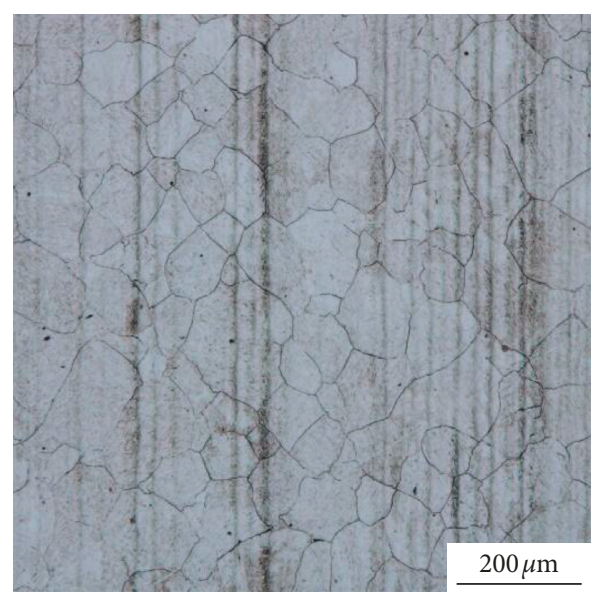

(a)

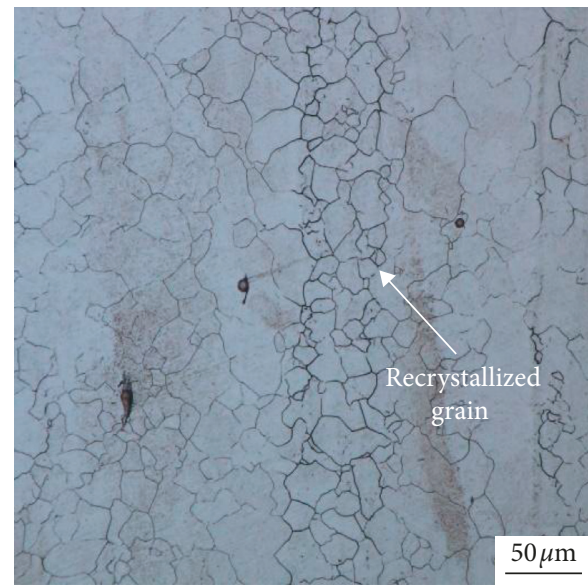

(c)

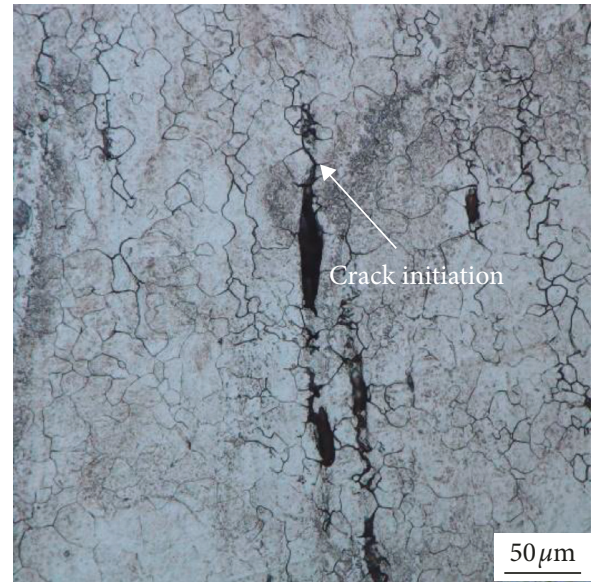

(e)

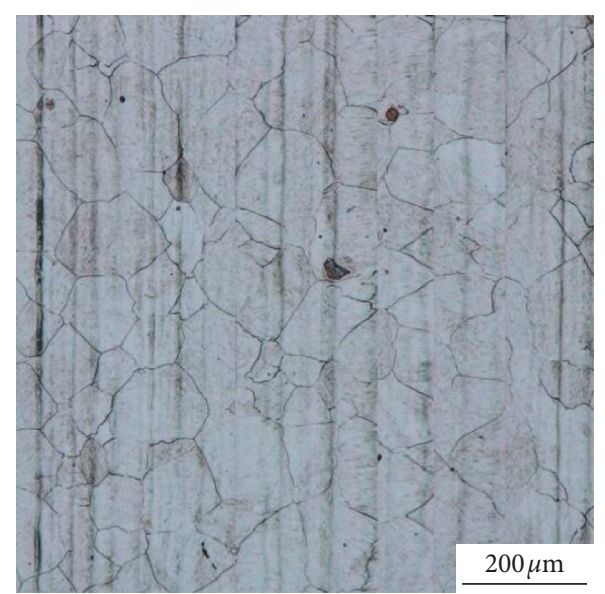

(b)

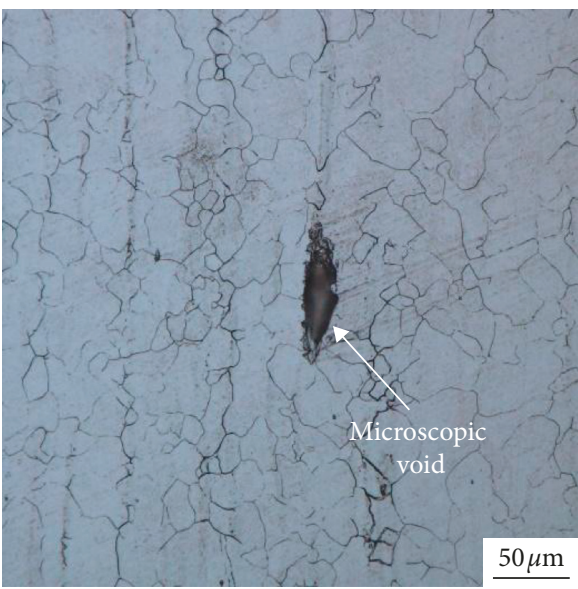

(d)

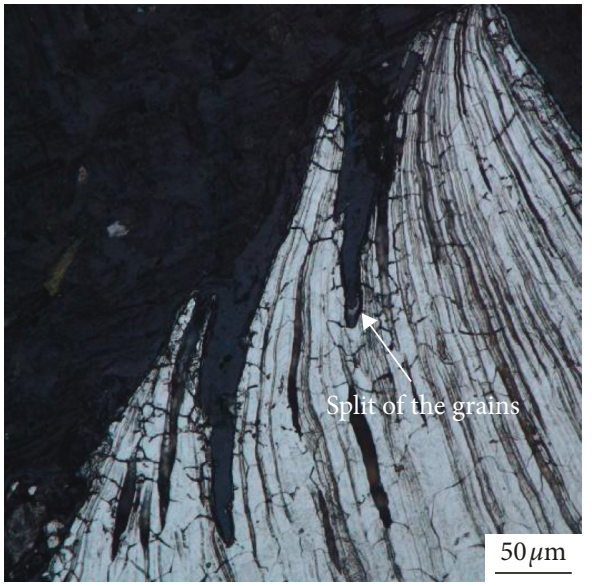

(f)

FiguRE 5: Microstructure transformation during the hot tensile process: (a) $\varepsilon=0.2$, (b) $\varepsilon=0.4$, (c) $\varepsilon=0.54$, (d) $\varepsilon=0.6$, (e) $\varepsilon=0.8$, and (f) $\varepsilon=0.97$.

and the initial notch radii $R$ are $6 \mathrm{~mm}, 4 \mathrm{~mm}, 2 \mathrm{~mm}$, and $1 \mathrm{~mm}$, respectively. According to formula (2), the corresponding initial stress triaxiality values are $0.55,0.65,0.89$, and 1.30 , respectively. In other words, the initial stress triaxiality increases with the decrease of the notch radius of the sample.

\section{Results and Discussion}

3.1. Cavity Nucleation and Crack Initiation. Figure 6 shows the tensile curves at various strain levels. In the initial stage of deformation, the stress increases rapidly until it has reached $40 \mathrm{MPa}$, and then the increase gradually becomes 


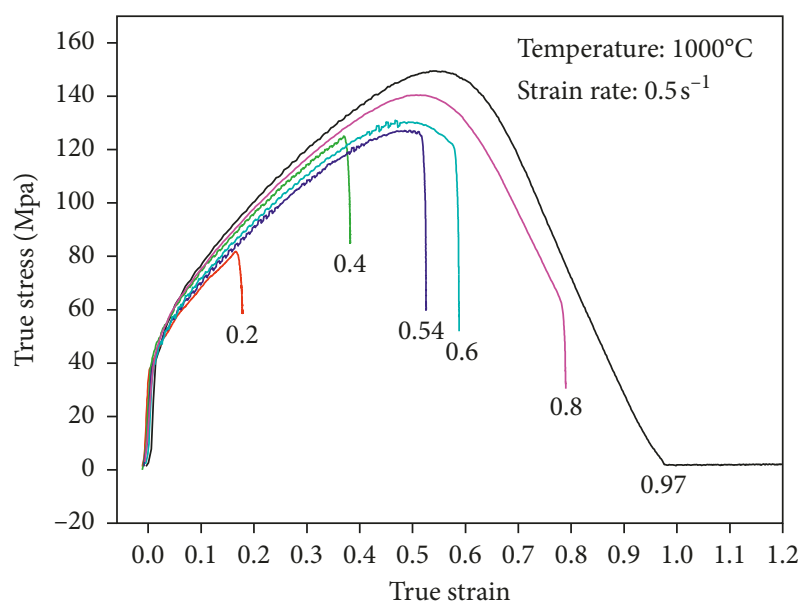

Figure 6: The true stress-strain curve at high temperatures.

gentle. The stress reaches its maximum value when the strain reaches 0.54 . Beyond this level, the stress decreases sharply as the strain increases. Figure 6 shows an experimental fracture strain of $\bar{\varepsilon}_{f}=0.97$.

The necking phenomenon is the significant contraction occurring in a local region of a sample when the applied load is maximized. As shown in Figure 7, necking becomes increasingly obvious as the strain increases. A stress peak appears in the tensile sample when the strain reaches 0.54 . Research has shown that the material begins to fail after this stress peak appears in tensile testing. Microcracks are formed in the sample, and necking is observed macroscopically. Once microcrack formation begins, additional external stress causes the development of macroscopic cracks and eventual material fracture and failure. The surface of the sample begins to show obvious macroscopic cracks when the strain reaches 0.6 . When the strain reaches 0.8 , necking is very serious. Although there are no obvious cracks formed in the sample at this time, the crack propagation within the sample is severe, as proven by the observation of the microstructure. As the strain continues to increase, fracture occurs at the value of 0.97 .

The microstructures of the hot deformation zones were observed after axial wire cutting of the $35 \mathrm{CrMo}$ steel samples to further understand the high-temperature plastic deformation crack initiation and propagation mechanisms. The results are shown in Figure 5.

When the strain reaches 0.2 and high-temperature plastic deformation begins, some austenite grains begin to grow. However, the strain is not yet sufficient to produce large microcracks. When the strain reaches 0.4 , the grains grow more than they do at the strain of 0.2 , and some tiny voids emerge in the microstructure. The stress peak appears when the strain reaches 0.54 . The grains are elongated in the axial direction, and many grains grow significantly. Because the amount of deformation is small, the number of recrystallized nuclei formed is small, and minute voids begin to form. Figure 5 shows that recrystallization occurs during void nucleation and growth. In addition, significant recrystallization nucleation initiation occurs at the grain boundaries when the strain increases to 0.6. At the same

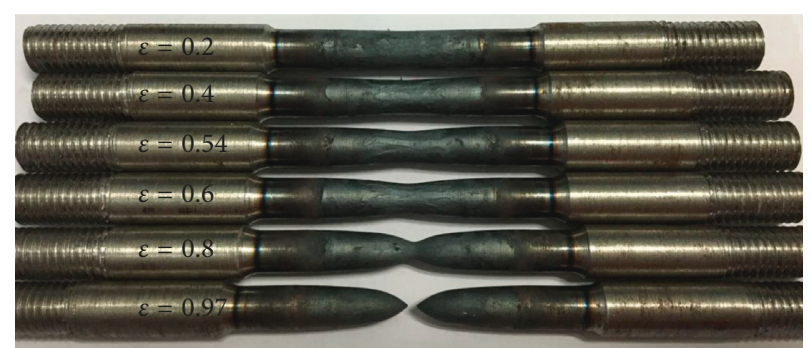

Figure 7: Samples after hot deformation: $\varepsilon=0.2, \varepsilon=0.4, \varepsilon=0.54$, $\varepsilon=0.6, \varepsilon=0.8$, and $\varepsilon=0.97$.

time, voids nucleate and form primarily in the axial direction. The voids grow further when the strain is increased to 0.8 , and all recrystallization occurs in the heat-affected zone. When the voids grow and converge, the strain reaches 0.97 and the samples undergo axial tensile stress fracture.

\subsection{Effect of Heterogeneous Phases on Voids Initiation.} Via the high-temperature thermal stretching and necking process, organization analysis can be determined. As shown in Figure 5(c), crack nucleation and initiation do not occur at the grain boundaries in 35CrMo steel, but rather in the grain interiors. High dislocation densities occur near the heterophases of the grains because of the high temperature and strain rate. This causes the dislocation density to increase where its product can accumulate easily. Voids are nucleated as the dislocation accumulation increases, and cracks form at the grain boundaries as the strain and stress concentration caused by cavity growth increases.

The fracture was observed using SEM to survey and evaluate the void nucleation mechanism. The resulting images are shown in Figure 8. The inclusions in molten steel are primarily composed of various deoxidizers such as $\mathrm{FeSi}$, $\mathrm{Al}$, and SiMn and refining agents such as $\mathrm{CaF}_{2}$ and $\mathrm{NaCl}$, which are oxidized to $\mathrm{Al}_{2} \mathrm{O}_{3}, \mathrm{SiO}_{2}, \mathrm{MnO}, \mathrm{Al}_{2} \mathrm{O}_{3}-\mathrm{SiO}_{2}-\mathrm{MnO}$, and $\mathrm{Ca}$ compounds during smelting. These endogenous inclusions can also form secondary deoxidization products during the latter solidification stages. These deoxidized oxides may not be able to precipitate from the ingot during subsequent cooling, thus forming inclusions. An inclusion particle was analyzed via energy-dispersive X-ray spectroscopy (EDS). As shown in Figure 8, the inclusions in $35 \mathrm{CrMo}$ steel are primarily endogenous. The alloying elements of $\mathrm{Ca}$ and $\mathrm{Al}$ are oxidized to form inclusions such as $\mathrm{Ca}$ compounds and $\mathrm{Al}_{2} \mathrm{O}_{3}$. Their effects on the mechanical properties, plasticity, toughness, and fatigue limit of the ingot are significant during thermal processing and heat treatment. These inclusions can cause stress concentration and microcrack formation, resulting in ingot failure. Therefore, the use of Al-containing deoxidizers and related Ca-containing refining agents should be strictly limited during the $35 \mathrm{CrMo}$ steel ingot melting process.

\subsection{Rheological Behavior and Fracture Strain of Different} Stress Triaxiality. Figure 9 shows the true stress-strain 

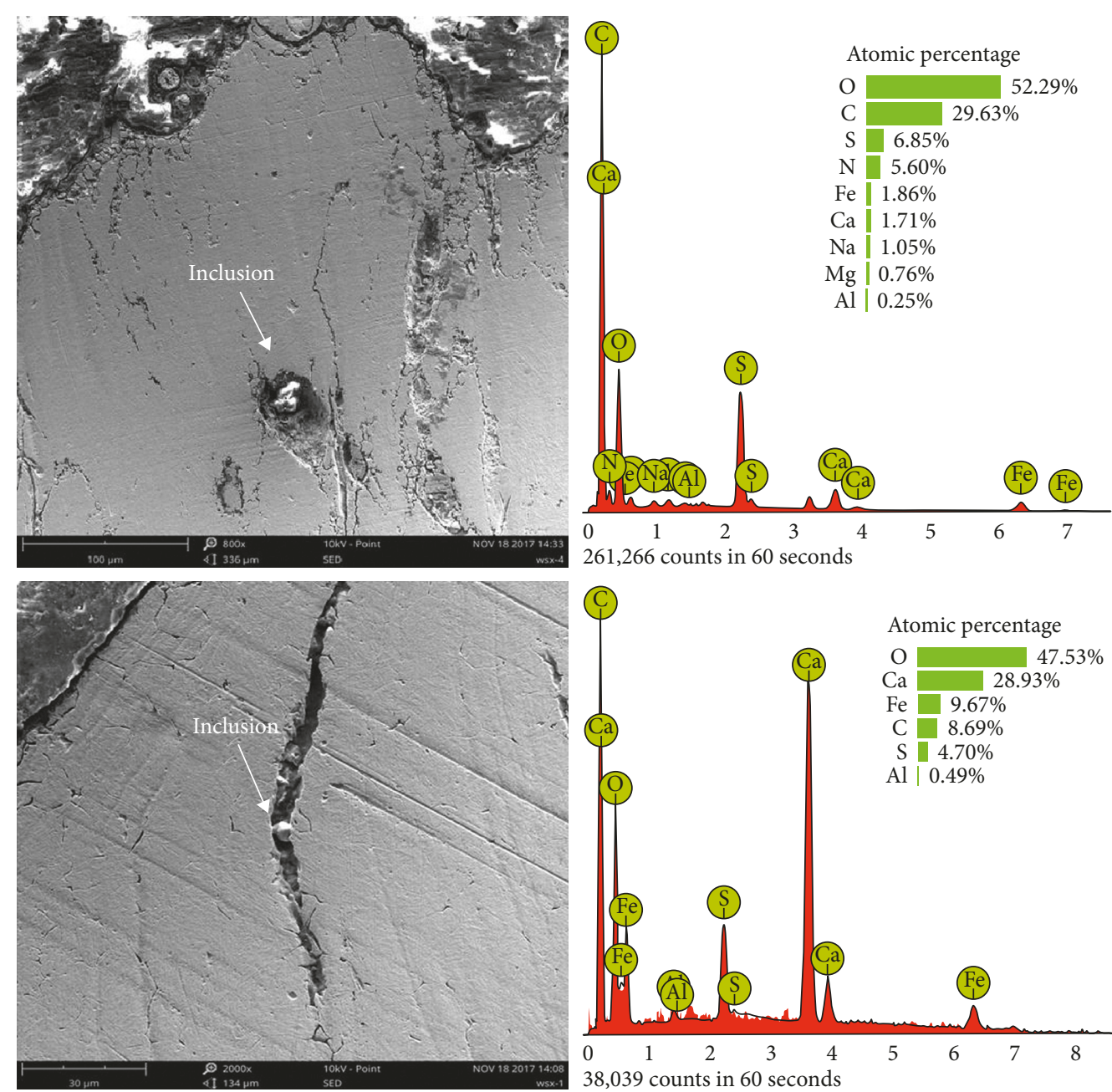

261,266 counts in 60 seconds

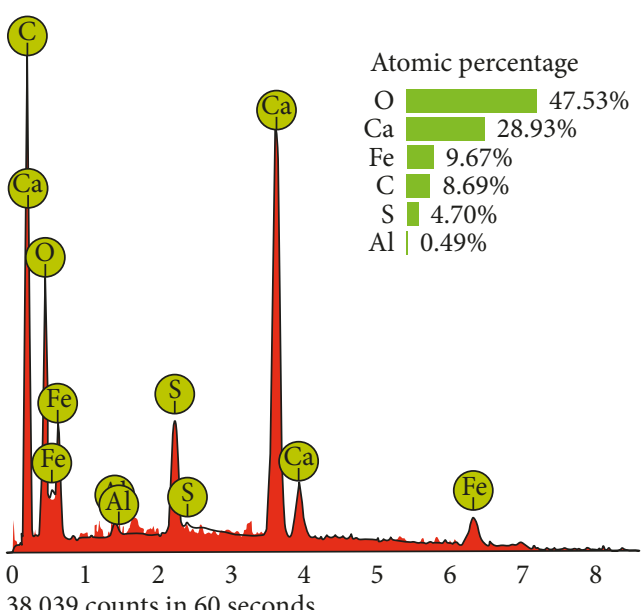

Figure 8: Chemical compositions of the inclusion particles.

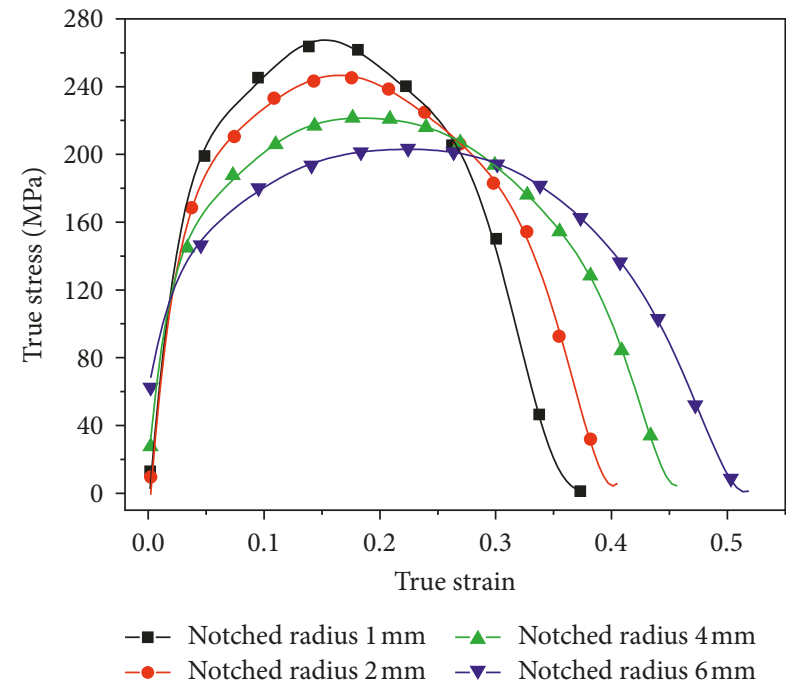

(a)

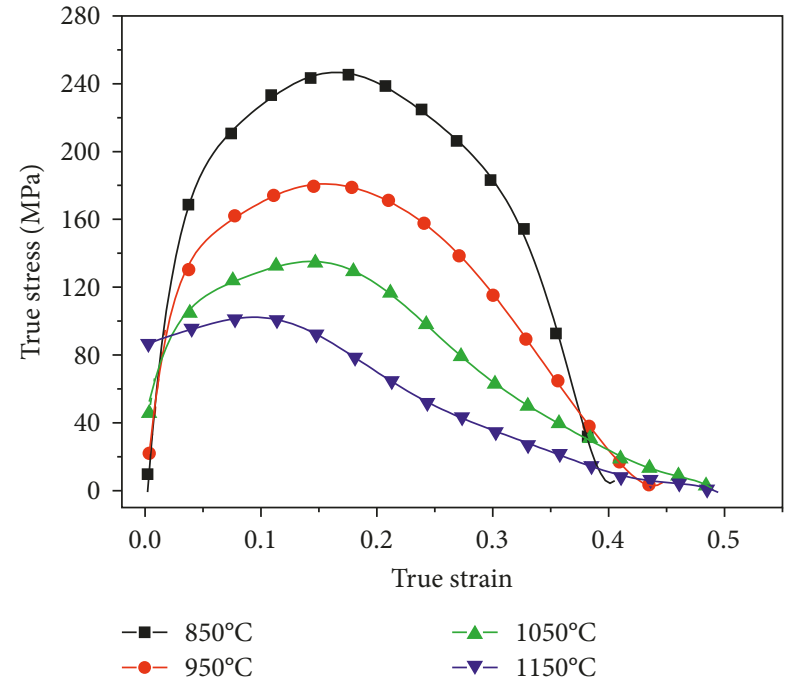

(b)

Figure 9: The true stress-strain curve of $35 \mathrm{CrMo}$ steel under different strain conditions: (a) $850^{\circ} \mathrm{C}$; (b) notched radius $2 \mathrm{~mm}$. 
curves of 35CrMo steel at different temperatures and notch radii at the strain rate of $0.5 \mathrm{~s}^{-1}$. At the beginning of tensile deformation, the stress growth is very rapid. When the strain is reached, the rheological stress increases slowly. As the tensile curves reach a certain strain, the initiation and accumulation of voids in the material rapidly weakens the material's resistance to deformation, and the rheological stress shows sharp decrease until material fracture occurs.

Figure 9(a) shows the true stress-true strain curves at $850^{\circ} \mathrm{C}$ for specimens with different notch radii. As shown in Figure 9(a), the stress reaches its peak value more quickly, and the peak stress is increased as the notch radius is decreased; in other words, samples with higher stress triaxiality reach the maximum stress earlier, and the peak stress values are higher than those of samples with lower stress triaxiality. Additionally, when the peak strain is reached, the stressstrain curve decreases rapidly under the condition of high stress triaxiality, and fracture occurs under the condition of lower strain levels. This phenomenon relates not only to the stress state of the material during the tensile process, but also to the degree of recrystallization in the matrix and the degree of dislocation annihilation. As shown in Figure 9(b), there is little difference in the overall strain range of the curve with increasing tensile temperature. Furthermore, the peak stress gradually decreases. The analysis indicates that under the condition of low stress triaxiality, sample deformation is uniform, and the accumulated energy in the deformation is more fully used for microstructure transformation. For example, the nucleation and growth of recrystallized grains and the enhancement of high-energy boundary activity at high tensile temperatures provide favorable conditions for dislocation elimination. Therefore, low stress triaxiality and high tensile temperatures are beneficial to decrease rheological resistance and increase the fracture strain.

The fracture strain value at high temperature is an important index reflecting the plastic deformation of the material. The effects of the notch radius and temperature on the fracture strain are shown in Figure 10. With the decrease of notch radius at the same tensile deformation temperature, the fracture strain decreases, that is, increased stress levels correspond to decreased material plasticity and easier material fracture under the same stress condition. In the same stress state, with the increase of the tensile deformation temperature, the fracture strain of the $35 \mathrm{CrMo}$ steel increases, the plasticity increases, and the fracture deformation resistance is strengthened.

3.4. Microstructural Observation and Analysis. Figure 11 shows the metallographic structure near the fracture surface of a notched tensile sample after testing at a strain rate of $0.5 \mathrm{~s}^{-1}$ and a tensile temperature of $850^{\circ} \mathrm{C}$. The notch radii are $6 \mathrm{~mm}, 4 \mathrm{~mm}, 2 \mathrm{~mm}$, and $1 \mathrm{~mm}$, respectively. Dynamic recrystallization occurs in all four notched radii regions. As the notch radius decreases, the recrystallization degree decreases with increasing stress triaxiality, and the grain size growth is slowed. At the notch radius of $6 \mathrm{~mm}$, recrystallization occurs more fully, but the dynamic recrystallization of the sample with the notch radius of $1 \mathrm{~mm}$

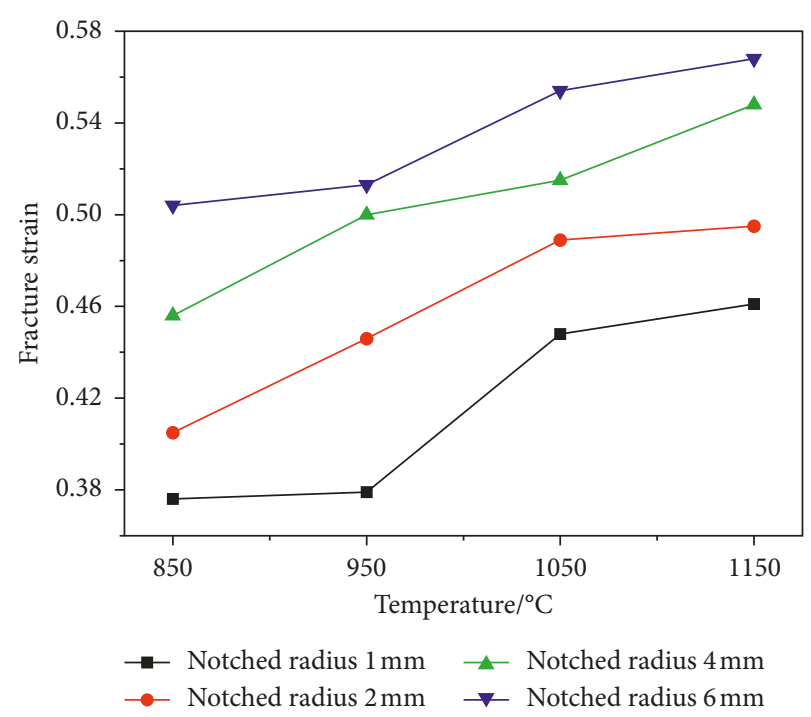

FIGURE 10: The fracture strain of the sample at different temperatures and notched radius is obtained, when the deformation rate is $0.5 \mathrm{~s}^{-1}$.

remains in the starting stage. The analysis shows that when the notch radius is $1 \mathrm{~mm}$, the stress triaxiality and strain concentration are both large. Strong deformation distortion can drive recrystallization nucleation, but because of the strong strain concentration, the recrystallization occurs before the material deforms. As a result, the grain structure after the final fracture is obviously finer than that of other samples, but with increased notch radius, the strain in the heat-affected zone becomes uniform, the fracture resistance is strengthened, and the fracture strain increases. The dynamic recrystallization becomes increasingly complete with increased deformation; as shown in Figure 11(a), the recrystallization of the sample with the notch radius of $6 \mathrm{~mm}$ is completed more fully.

3.5. Fracture Scanning and Analysis. The samples from which the rheological curves in Figure 9 were obtained at the temperature of $850^{\circ} \mathrm{C}$, and the notch radius of $2 \mathrm{~mm}$ were observed using SEM. The resulting images are shown in Figures 12 and 13. Under the selected reference conditions, the fracture mechanism and influence law of different stress states and deformation temperatures on the samples can be further explained.

As shown in Figure 12, when the deformation temperature is $850^{\circ} \mathrm{C}$, the sections in different stress states are occupied by dimples of different sizes. The dimples are macroscopic features reflecting the growth and convergence of internal voids in the plastic deformation of materials. This demonstrates once again that the tensile failure of $35 \mathrm{CrMo}$ steel occurs by typical ductile fracture. Ductile fracture occurs in different forms after considering the factors of void rotation and changes in void shape, but the basic process is similar. They all occur in the normal stress state with normal stress triaxiality and rough dimples on the fracture surface. The stress-strain curves show that the fracture strains are decreased with increasing stress triaxiality, which is obvious and 


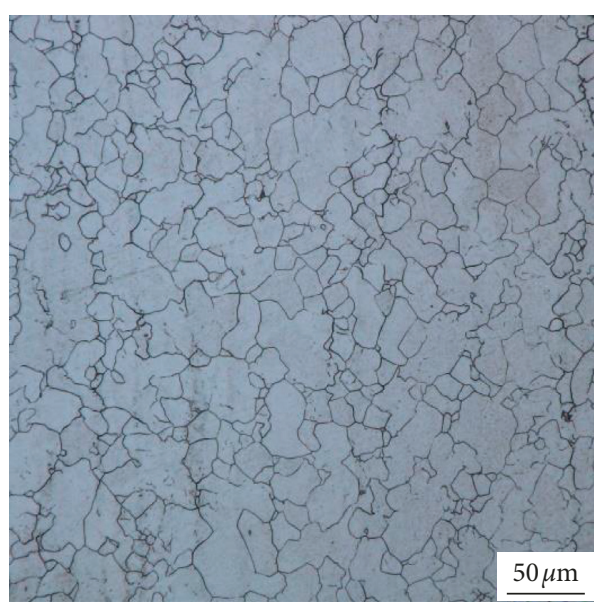

(a)

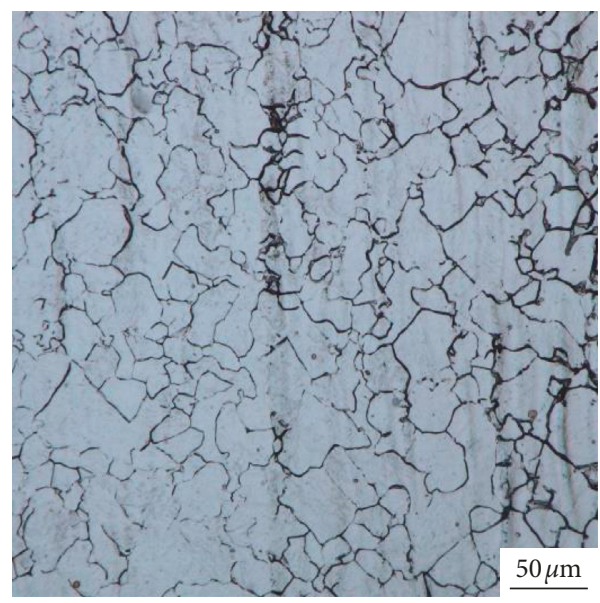

(c)

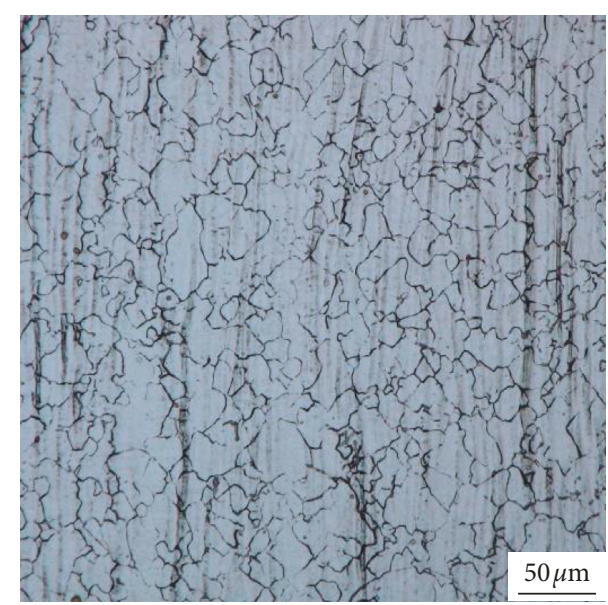

(b)

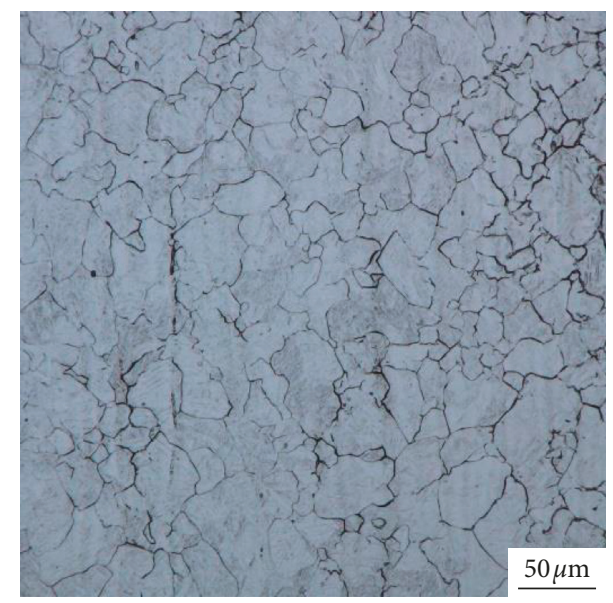

(d)

FIgURE 11: The metallographic structure near the fracture surface of notched tensile samples at a strain rate of $0.5 \mathrm{~s}^{-1}$ and a tensile temperature of $850^{\circ} \mathrm{C}$ : (a) $6 \mathrm{~mm}$, (b) $4 \mathrm{~mm}$, (c) $2 \mathrm{~mm}$, and (d) $1 \mathrm{~mm}$.

reflected by the microscopic void growth. As shown in Figure 12 , as the radius of the notch decreases, that is, as the stress triaxiality increases, the diameters and depths of the dimples are decreased. This is because higher degrees of stress triaxiality produce greater stress concentrations in the material, and fracture occurs at smaller strains. The voids in the material initiated under tensile stress do not accumulate and grow, nor do they extend along the tensile direction. Instead, as the stress triaxiality decreases, the fracture strain of the material increases, the time of deformation increases for the same strain rate, and the voids in the material grow and accumulate. Thus, the dimples are large and deep in the cross section.

Figure 13 shows the fracture-scanning morphology of samples strained at temperatures from $850^{\circ} \mathrm{C}$ to $1150^{\circ} \mathrm{C}$ with the notch radius of $2 \mathrm{~mm}$. Under the same stress state, the deformation temperature has a significant effect on the shrinkage of the cross section of the material. It is shown that the shrinkage rate of the section is increased sharply with increasing temperature, and the necking ability of $35 \mathrm{CrMo}$ steel is obviously improved with increasing temperature.

When the deformation temperature is $850^{\circ} \mathrm{C}$, the dimples are shallow and different in size. At this lower temperature, the combined deformation ability and necking ability of adjacent dimples is decreased, which decreases the damage tolerance of the material. With increased deformation temperature, the wall of dimples between adjacent dimples is torn, and the number of dimples is gradually decreased. Because of the increase of temperature, the fracture strain of the materials is increased, thereby allowing sufficient time for the growth and accumulation of microvoids, especially in the tensile direction, where the dimples gradually deepen. Finally, the dimples merge into one dimple, thus allowing the individual dimples to grow. As shown in Figure 13, when the temperature reaches $1050^{\circ} \mathrm{C}$ and $1150^{\circ} \mathrm{C}$, the number of dimples on the fracture section decreases sharply, and the dimples obviously increase and deepen, demonstrating the good plasticity of $35 \mathrm{CrMo}$ steel at high temperatures. The dimple wall under high-temperature deformation shows obvious slip characteristics, which is a significant feature of large plastic strain, which also explains the phenomenon of the increased fracture strain value in the rheological stress curve with increased temperature, that is, the damage capacity limit of the material is enhanced at higher temperatures. 


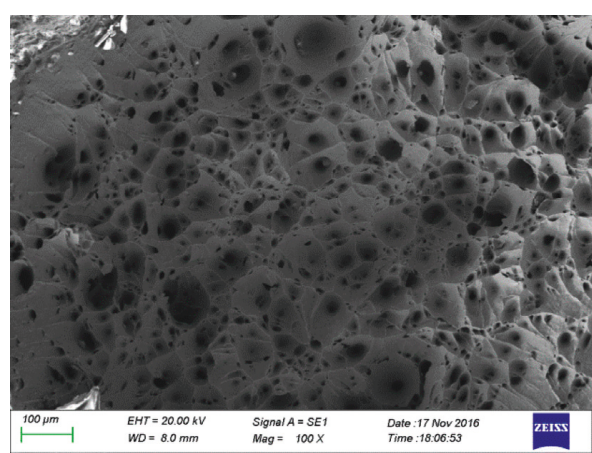

(a)

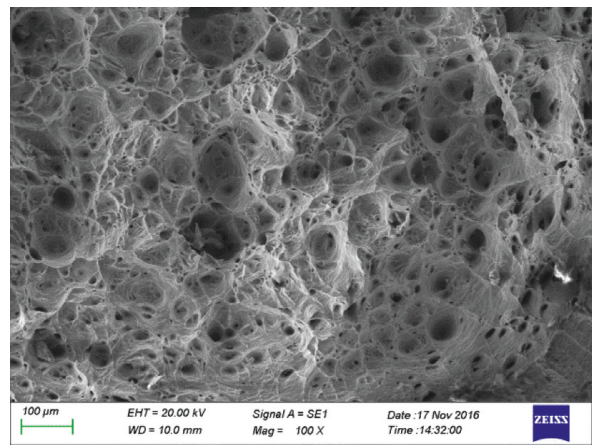

(c)

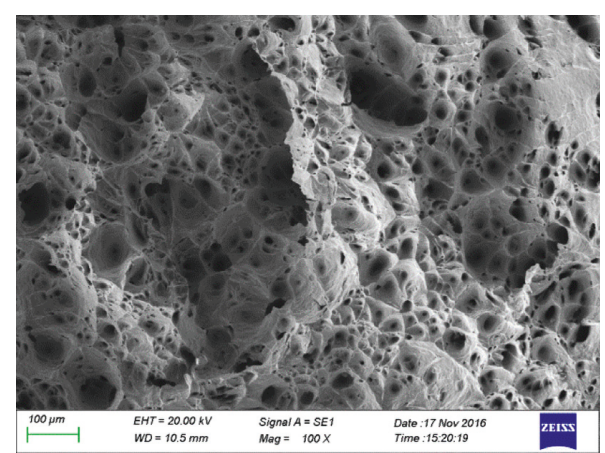

(b)

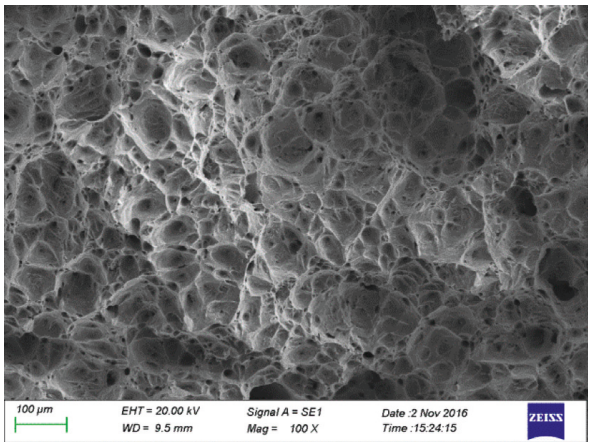

(d)

Figure 12: The fracture morphology of different notched samples at a tensile temperature of $850^{\circ} \mathrm{C}$ : (a) $6 \mathrm{~mm}$, (b) $4 \mathrm{~mm}$, (c) $2 \mathrm{~mm}$, and (d) $1 \mathrm{~mm}$.

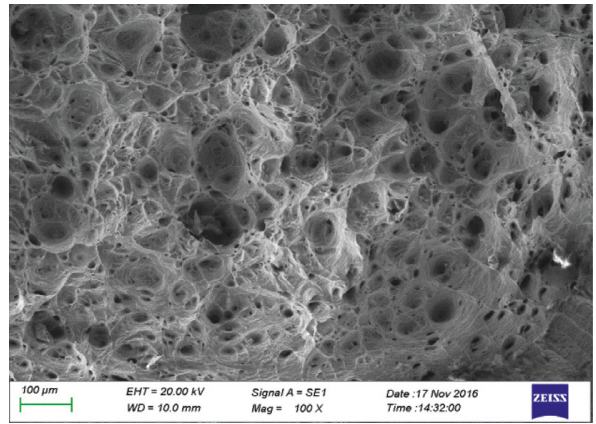

(a)

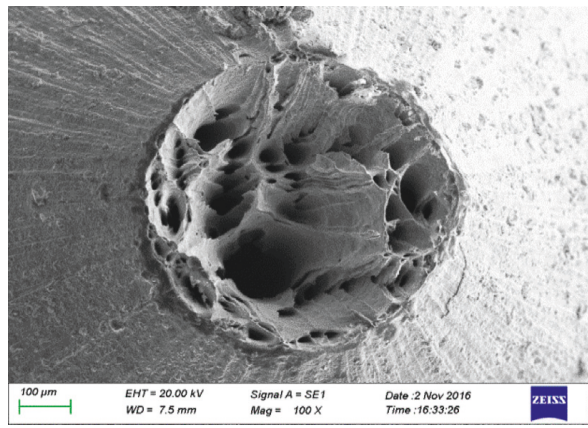

(c)

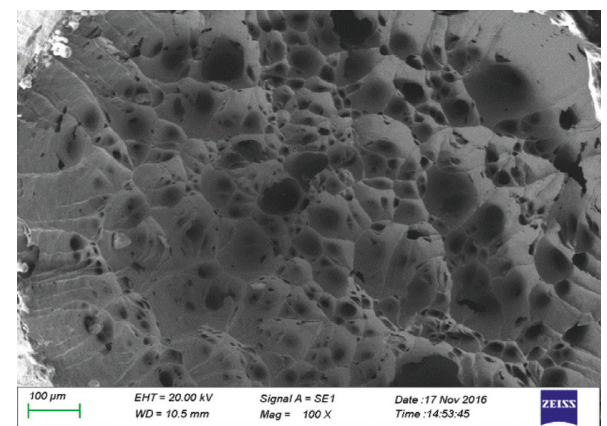

(b)

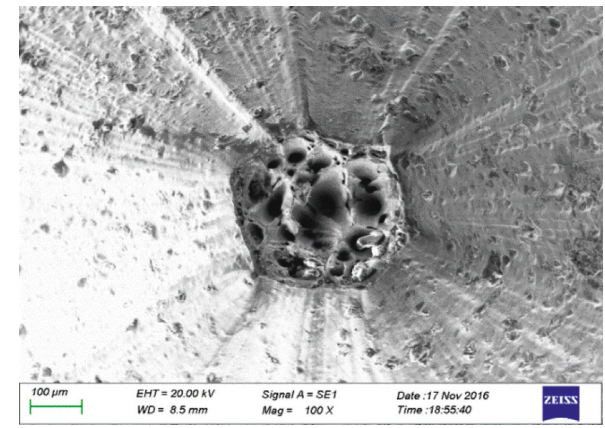

(d)

FIGURE 13: The fracture morphology of samples with notch radius of $2 \mathrm{~mm}$ at different temperatures: (a) $850^{\circ} \mathrm{C}$, (b) $950^{\circ} \mathrm{C}$, (c) $1050^{\circ} \mathrm{C}$, and (d) $1150^{\circ} \mathrm{C}$. 


\section{Conclusions}

Tensile tests and tensile unloading experiments were conducted to investigate the crack initiation and fracture behavior of 35CrMo steel. The main conclusions are as follows:

(1) Crack formation in 35CrMo steel proceeds by the nucleation, growth, and coalescence of microcavities during high-temperature tensile processing. With the superposition of the dislocation density, stress concentrations are produced by grain heterogeneity, and cavity nucleation occurs first. The process of void growth and coalescence leads to the fracture of the material. Inclusions, such as compounds of $\mathrm{Ca}$ and $\mathrm{Al}_{2} \mathrm{O}_{3}$, are the main heterogeneous phases that cause cavity nucleation.

(2) The effect of stress triaxiality on the rheological behavior of $35 \mathrm{CrMo}$ steel is very significant. The sample with higher stress triaxiality reaches the peak stress first, and the peak stress is higher than that of the sample with lower stress triaxiality, and the fracture strain is lower. The temperature has little effect on the fracture strain range of 35CrMo steel, but the fracture strain increases slightly with increasing tensile temperature.

(3) At the same tensile deformation temperature, the recrystallization degree of the steel decreases with the increase of stress triaxiality; the dynamic recrystallization grain size is large while the dimples in the fracture surface are small and shallow. However, the temperature is mainly reflected in the shrinkage rate of the section; the 35CrMo steel exhibits good plasticity at high temperature, and the fracture dimple is large and deep.

\section{Data Availability}

The data in the manuscript are all from experiments. The picture data used to support the findings of this study are included within the article. Finally, the curve data used to support the findings of this study are available from the corresponding author upon request.

\section{Conflicts of Interest}

The authors declare no conflicts of interest.

\section{Authors' Contributions}

Zheng Li and Sanxing Wang conceived and designed the experiments; Sanxing Wang carried out the experiments; Zheng Li and Sanxing Wang analyzed the data; Yajun Zhou contributed reagents, materials, and analysis tools; and Zheng Li wrote the paper.

\section{Acknowledgments}

The authors are grateful for financial support by the Fundamental Research Funds for the Central Universities of
Central South University (2018zzts477) and the National Program on Key Basic Research Project of China (No. 2014CB046702).

\section{References}

[1] Y. Lv, "Influence of laser surface melting on the micropitting performance of 35CrMo structural steel gears," Materials Science and Engineering A, vol. 564, pp. 1-7, 2013.

[2] J. W. Zhang, L. T. Lu, P. B. Wu, J. J. Ma, G. G. Wang, and W. H. Zhang, "Inclusion size evaluation and fatigue strength analysis of 35CrMo alloy railway axle steel," Materials Science and Engineering A, vol. 562, pp. 211-217, 2013.

[3] G. Liang, C. Shi, Y. Zhou, and D. Mao, "Effect of ultrasonic treatment on the solidification microstructure of die-cast 35CrMo steel," Metals, vol. 6, no. 11, p. 260, 2016.

[4] J. Chen, Y. Zhou, C. Shi, and D. Mao, "Microscopic analysis and electrochemical behavior of Fe-based coating produced by laser cladding," Metals, vol. 7, no. 10, p. 435, 2017.

[5] Z. Xiao, Y. Huang, and Y. Liu, "Evolution of dynamic recrystallization in 35CrMo steel during hot deformation," Journal of Materials Engineering and Performance, vol. 27, no. 3, pp. 924-932, 2018.

[6] A. Y. Churyumov, M. G. Khomutov, A. N. Solonin, A. V. Pozdniakov, T. A. Churyumova, and B. F. Minyaylo, "Hot deformation behaviour and fracture of $10 \mathrm{CrMoWNb}$ ferritic-martensitic steel," Materials and Design, vol. 74, pp. 44-54, 2015.

[7] P. Ludwik and R. Scheu, "Ueber kerbwirkungen bei flusseisen," Stahl und Eisen, vol. 43, pp. 999-1001, 1923.

[8] P. K. Liaw, C. Y. Yang, S. S. Palusamy, and W. Ren, "Fatigue crack initiation and propagation behavior of pressure vessel steels," Engineering Fracture Mechanics, vol. 57, no. 1, pp. 85-104, 1997.

[9] T. Pardoen and J. W. Hutchinson, "An extended model for void growth and coalescence," Journal of the Mechanics and Physics of Solids, vol. 48, no. 12, pp. 2467-2512, 2000.

[10] Y. Zhang, "Magnetic relaxation behavior in Tb-doped perovskite manganite," Journal of Magnetism and Magnetic Materials, vol. 323, no. 1, pp. 1-3, 2011.

[11] A. A. Benzerga, "Micromechanics of coalescence in ductile fracture," Journal of the Mechanics and Physics of Solids, vol. 50, no. 6, pp. 1331-1362, 2002.

[12] X. Gao and J. Kim, "Modeling of ductile fracture: significance of void coalescence," International Journal of Solids and Structures, vol. 43, no. 20, pp. 6277-6293, 2006.

[13] J. Choung, C. S. Shim, and H. C. Song, "Estimation of failure strain of EH36 high strength marine structural steel using average stress triaxiality," Marine Structures, vol. 29, no. 1, pp. 1-21, 2012.

[14] Y. C. Lin, J. Deng, Y. Q. Jiang, D. X. Wen, and G. Liu, "Hot tensile deformation behaviors and fracture characteristics of a typical Ni-based superalloy," Materials \& Design, vol. 55, pp. 949-957, 2014.

[15] Z. Man, Z. Jian, L. Yao, C. Liu, G. Yang, and Y. Zhou, "Effect of mischmetal modification treatment on the microstructure, tensile properties, and fracture behavior of $\mathrm{Al}-7.0 \% \mathrm{Si}-0.3 \% \mathrm{Mg}$ foundry aluminum alloys," Journal of Materials Science, vol. 46, no. 8, pp. 2685-2694, 2011.

[16] L. Wang, H. Yu, and Y. S. Lee, "Effect of microstructure on hot tensile deformation behavior of 7075 alloy sheet fabricated by twin roll casting," Materials Science and Engineering A, vol. 652, pp. 221-230, 2016. 
[17] M. Zhou, Y. C. Lin, J. Deng, and Y. Q. Jiang, "Hot tensile deformation behaviors and constitutive model of an Al-ZnMg-Cu alloy,” Materials \& Design, vol. 59, pp. 141-150, 2014.

[18] X. Zhang, Y. Zhang, Y. Li, and J. Liu, "Cracking initiation mechanism of 316LN stainless steel in the process of the hot deformation," Materials Science and Engineering A, vol. 559, pp. 301-306, 2013.

[19] X. W. Duan and J. S. Liu, "Research on damage evolution and damage model of 316LN steel during forging," Materials Science and Engineering A, vol. 588, pp. 265-271, 2013.

[20] F. A. Mcclintock, "A criterion for ductile fracture by the growth of holes," Journal of Applied Mechanics, vol. 35, no. 2, pp. 363-371, 1968.

[21] J. R. Rice and D. M. Tracey, "On the ductile enlargement of voids in triaxial stress fields*," Journal of the Mechanics and Physics of Solids, vol. 17, no. 3, pp. 201-217, 1969.

[22] J. W. Hancock and A. C. Mackenzie, "On the mechanisms of ductile failure in high-strength steels subjected to multi-axial stress-states," Journal of the Mechanics and Physics of Solids, vol. 24, no. 2-3, pp. 147-160, 1976.

[23] M. S. Mirza, D. C. Barton, and P. Church, "The effect of stress triaxiality and strain-rate on the fracture characteristics of ductile metals," Journal of Materials Science, vol. 31, no. 2, pp. 453-461, 1996.

[24] Y. Bao and R. Treitler, "Ductile crack formation on notched Al2024-T351 bars under compression-tension loading," Materials Science and Engineering A, vol. 384, no. 1-2, pp. 385-394, 2004.

[25] Y. Bao and T. Wierzbicki, "On fracture locus in the equivalent strain and stress triaxiality space," International Journal of Mechanical Sciences, vol. 46, no. 1, pp. 81-98, 2004.

[26] Y. Bao, "Dependence of ductile crack formation in tensile tests on stress triaxiality, stress and strain ratios," Engineering Fracture Mechanics, vol. 72, no. 4, pp. 505-522, 2005.

[27] Y. Bao and T. Wierzbicki, "On the cut-off value of negative triaxiality for fracture," Engineering Fracture Mechanics, vol. 72, no. 7, pp. 1049-1069, 2005.

[28] Z. Xiao, Y. Huang, H. Liu, and S. Wang, "Hot tensile and fracture behavior of 35CrMo steel at elevated temperature and strain rate," Metals, vol. 6, no. 9, p. 210, 2016.

[29] P. W. Bridgman, Studies in Large Plastic Flow and Fracture with Special Emphasis on the Effects of Hydrostatic Pressure, Harvard University Press, Cambridge, MA, USA, 1964. 


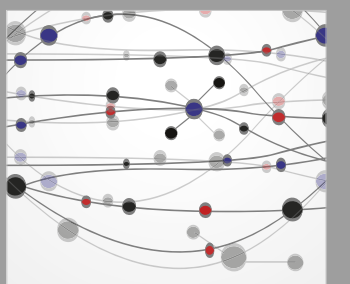

The Scientific World Journal
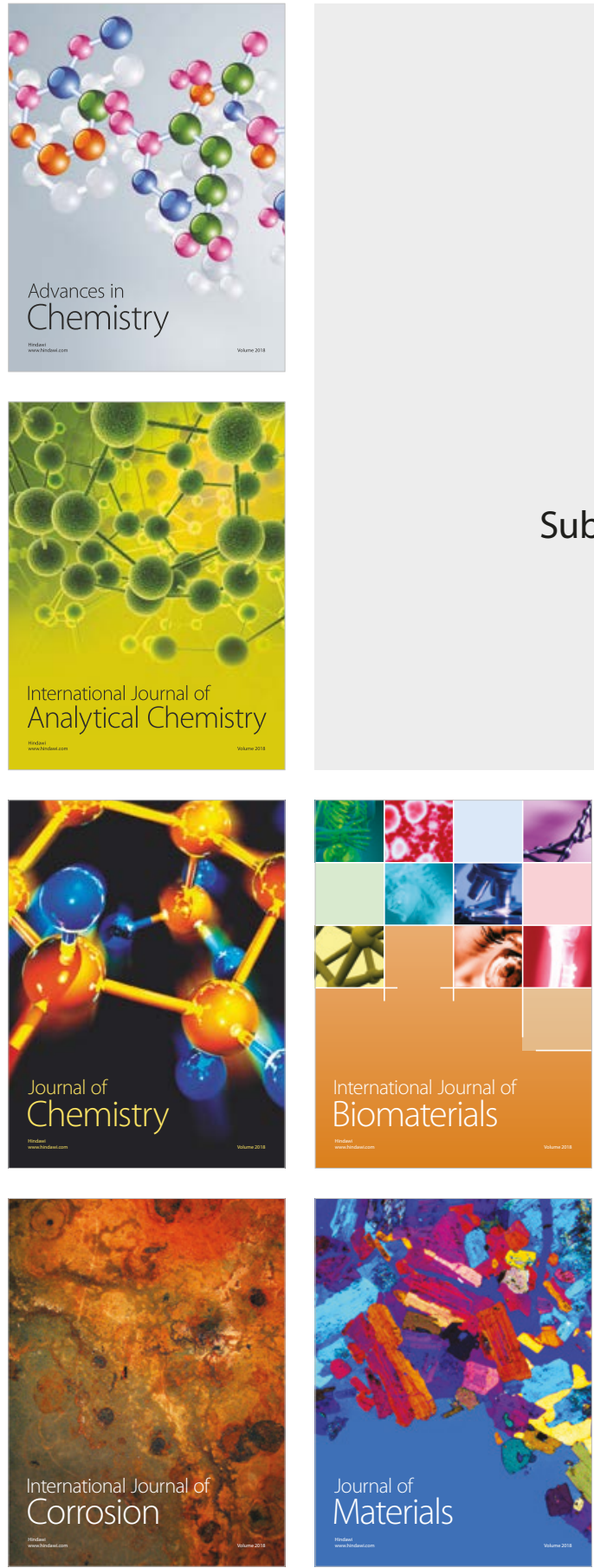

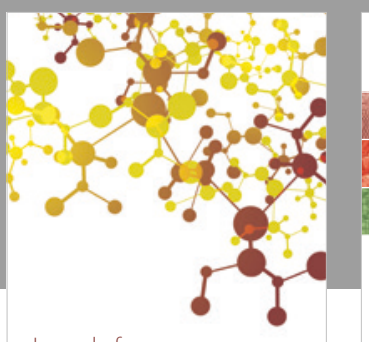

Journal of

Applied Chemistry
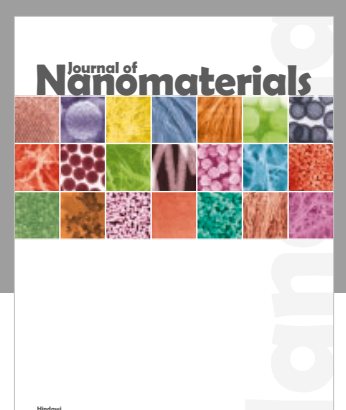

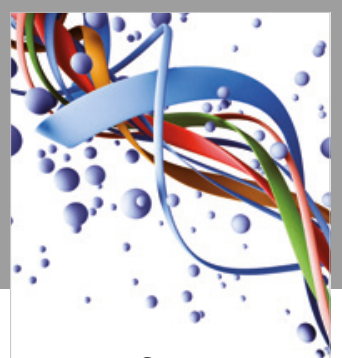

Scientifica

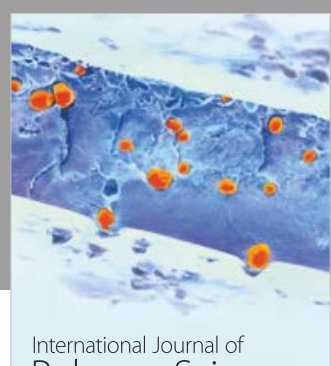

Polymer Science

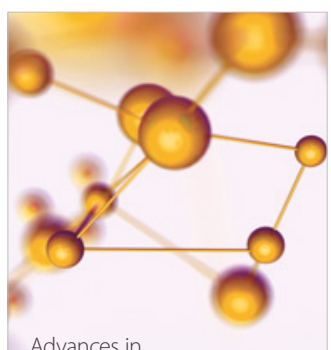

Physical Chemistry
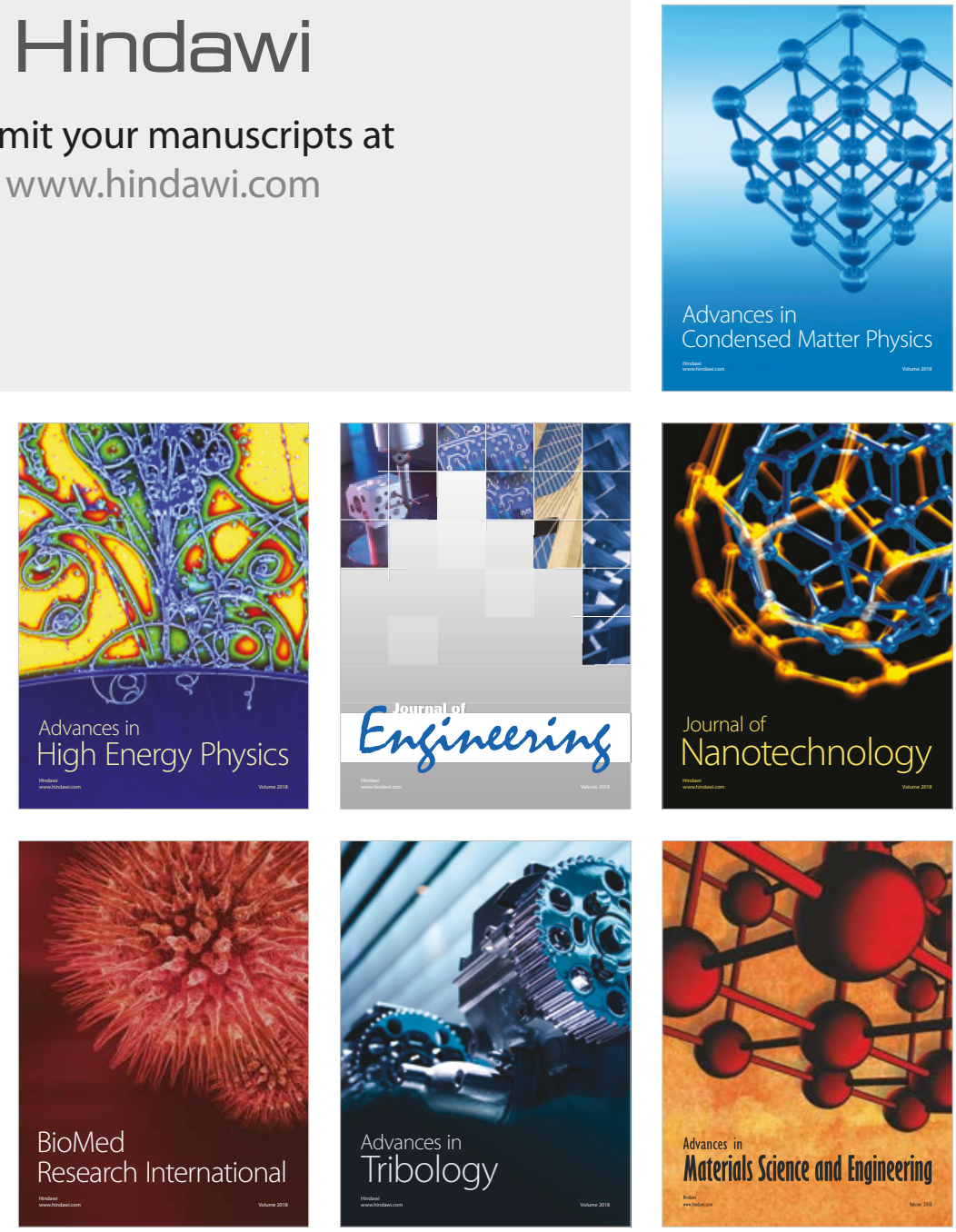